\title{
Effect of Welding Passes on Heat Affected Zone and Tensile Properties of AISI 304 Stainless Steel and Chrome-Manganese Austenitic Stainless Steel
}

\author{
Ravindra V. TAIWADE, ${ }^{1) *}$ Awanikumar P. PATIL, ${ }^{1)}$ Ravindra D. GHUGAL, ${ }^{1)}$ Suhas J. PATRE ${ }^{2)}$ \\ and Ravin K. DAYAL ${ }^{3)}$ \\ 1) Department of Metallurgical and Materials Engineering, Visvesvaraya National Institute of Technology, Nagpur, 440010 India. \\ 2) Department of Mechanical Engineering, Visvesvaraya National Institute of Technology, Nagpur, 440010 India. \\ 3) School of Mechanical and Building Sciences, VIT University, Chennai, 600048 India.
}

(Received on June 25, 2012; accepted on September 12, 2012)

\begin{abstract}
This paper aims at a systematic comparison of effect of single, double and triple pass welding on heat affected zone and tensile strength of AISI 304 stainless steel and chrome-manganese austenitic stainless steel. Degree of sensitization (DOS) increased with increase in number of passes and highest DOS $(35.53 \%)$ was obtained for triple pass welding of chrome-manganese austenitic stainless steel. The decrease in tensile strength is relatively more in chrome-manganese austenitic stainless steel as compared to AISI 304 SS. The mode of failure for AISI 304 SS was ductile fracture, whereas chrome-manganese austenitic stainless steel failed due to intergranular brittle fracture.
\end{abstract}

KEY WORDS: AISI 304 stainless steel; chrome-manganese austenitic stainless steel; shielded metal arc welding; heat affected zone; fractography; electron probe micro analysis.

\section{Introduction}

Austenitic stainless steels (ASS) have wide applications in many industries due to its excellent combination of corrosion resistance and mechanical properties. ${ }^{1,2)}$ Corrosion resistance is provided by a very thin invisible passive film of $\mathrm{Cr}_{2} \mathrm{O}_{3}$, formed on the surface of ASS, when exposed to ambient environment. ${ }^{3)}$ The ASS family is classified into two categories viz. 300-series and 200-series stainless steels. AISI 304 and 316 SS are the most popularly used grades of 300-series stainless steel. ${ }^{1,4)}$ In 200-series, manganese is introduced in addition to nickel, which acts as an austenite stabilizer, and hence the nickel content in 200series is lower than in 300 -series. ${ }^{5,6)} 200$-series steels are economical than 300-series, but they do not have same level of corrosion resistance and weldability as compared to 300series. ${ }^{7}$ 200-series is the fastest growing variety of stainless steels in recent years and currently account for more than $10 \%$ of the total stainless steel production. ${ }^{8,9)}$ The future will place greater demands on 200-series alloys in replacement of 300-series for variety of applications such as home accessories, office appliances, light poles, construction, outdoor installations, etc., where high corrosion resistance is not required. ${ }^{1,7,9,10)}$ These steels are also known as "ChromeManganese" ASS (Cr-Mn ASS). ${ }^{10)}$ When the ASS family is subjected to slow heating or cooling in the temperature range of $450^{\circ} \mathrm{C}-900^{\circ} \mathrm{C}$, complex carbides $(\mathrm{Fe}, \mathrm{Cr})_{23} \mathrm{C}_{6}$ are

* Corresponding author: E-mail: rvtaiwadevnit@gmail.com DOI: http://dx.doi.org/10.2355/isijinternational.53.102 precipitated at the grain boundaries. This leads to chromium depletion adjacent to the grain boundaries. ${ }^{1,11,12)}$ When the concentration of chromium in the matrix becomes less than $10-11 \mathrm{wt} \%$, the film of $\mathrm{Cr}_{2} \mathrm{O}_{3}$ is not passive enough to protect ASS and therefore it becomes susceptible to intergranular corrosion (IGC) and this phenomenon is known as "sensitization". 12,13)

Welding is the most common fabrication process used for ASS in various industries. ASS is generally considered to have very good weldability. ${ }^{14)}$ Shielded metal arc welding (SMAW) and tungsten inert gas welding (TIG) are the most commonly used welding process for ASS. ${ }^{14,15)}$ During welding, a certain portion of base metal experiences peak temperatures high enough to develop microstructural changes viz. phase-transformation, grain growth, etc. These microstructural changes have detrimental effects on the mechanical properties of weldment. This part of base metal is commonly referred to as "Heat Affected Zone (HAZ)". In case of ASS, chromium carbide precipitates along grain boundaries in the HAZ, which leads to IGC. ${ }^{415-17)}$ Various researchers have studied the effect of welding on the formation of HAZ in 300-series ASS. ${ }^{18-21)}$ Subodh Kumar et al. $^{22)}$ studied the effect of three different heat inputs on the microstructure and mechanical properties of gas tungsten arc welded AISI 304 stainless steel joints. They concluded that the tensile strength decreases with increase in heat input. But, the literature related to welding behavior and subsequent mechanical properties of 200-series ASS is scanty till now. The authors in their previous work ${ }^{5)}$ carried out studies on beadon-plate welding with single heat input on $\mathrm{Cr}-\mathrm{Mn}$ ASS and 
concluded that it gets sensitized during welding and width of HAZ was measured as $2 \mathrm{~mm}$. As already mentioned, the corrosion behavior and mechanical properties of $\mathrm{Cr}-\mathrm{Mn}$ ASS is not same as in 300-series, hence, the authors were interested to investigate the welding behavior of both the steels for single and multipass welding, and also the tensile properties of the welded steels.

\section{Experimental Work}

The AISI 304 SS and Cr-Mn ASS were procured from market in the form of sheet. Their typical chemical composition as determined by optical emission spectrometer is presented in Table 1. Plates of size $150 \mathrm{~mm} \times 75 \mathrm{~mm} \times 3 \mathrm{~mm}$ were obtained using wire-cut electrical discharge machine (WEDM) from AISI 304 SS (3 Nos.) and Cr-Mn ASS (3 Nos.). These plates were solution annealed in muffle furnace at a temperature of $1050^{\circ} \mathrm{C}$ for 1 hour, followed by water quenching. ${ }^{23)}$ Then, the plates were polished up to 600 grit to remove oxide layer formed due to solution annealing. Bead-on-plate SMAW was performed along the centre line (see Fig. 1) of the solution annealed plates using the electrode "AWS E308L-16" of diameter $3.15 \mathrm{~mm}^{24)}$ The electrodes were baked at $200^{\circ} \mathrm{C}$ in the oven for 45 minutes before welding, to remove moisture. Single, double and triple passes were carried out at a uniform speed by an experienced welding operator. Two minutes rest time was given between the successive passes. ${ }^{25)}$ The slag formed during welding was removed in this rest time. The heat input was kept constant for all the passes. Heat input per mm length of weld ' $Q$ ' was calculated using welding variables and by considering arc efficiency $(\eta)$ of $0.75 .^{15,25)}$

$$
\mathrm{Q}=(\eta \mathrm{V} \mathrm{I} / \mathrm{v})
$$

where, "V" is arc voltage in volts (V),

"I" is welding current in amperes (A),

" $\mathrm{v}$ " is speed of welding in $\mathrm{mm} / \mathrm{s} .{ }^{17}$ )

Following welding parameters were used in this study:

Table 1. Chemical composition (wt $\%$ ) of studied steels.

\begin{tabular}{l|ccccccc}
\hline Elements & $\mathrm{C}$ & $\mathrm{Cr}$ & $\mathrm{Ni}$ & $\mathrm{Mn}$ & $\mathrm{Si}$ & $\mathrm{P}$ & $\mathrm{S}$ \\
\hline AISI 304 SS & 0.054 & 20.01 & 7.97 & 1.11 & 0.510 & 0.0281 & 0.0061 \\
Cr-Mn ASS & 0.11 & 15.86 & 0.3098 & 9.60 & 0.434 & 0.0378 & 0.0041 \\
\hline
\end{tabular}

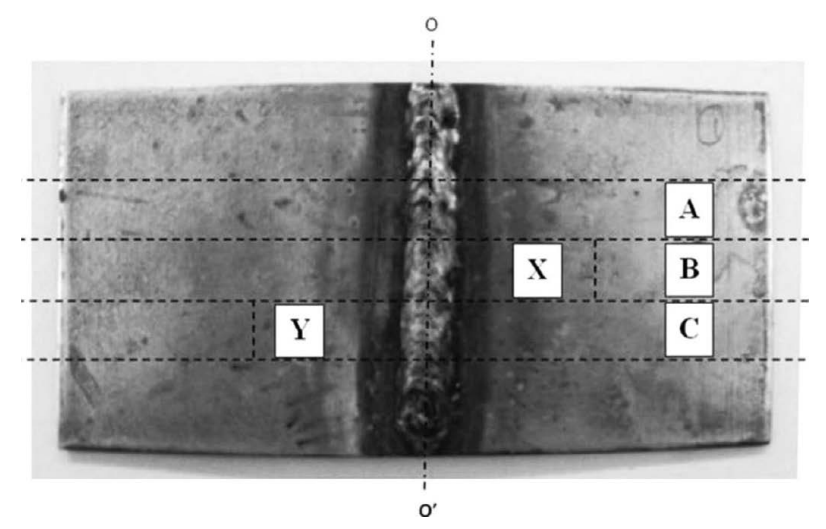

Fig. 1. Bead-on-plate shielded metal arc welding.
Welding current $-75 \mathrm{~A}$, arc voltage $-35 \mathrm{~V}$ and welding speed (v) $-2.57 \mathrm{~mm} / \mathrm{s}$.

Three samples of size $150 \mathrm{~mm} \times 10 \mathrm{~mm} \times 3 \mathrm{~mm}$ were obtained carefully from the welded plate using WEDM. These samples were denoted by A, B and C as shown in Fig. 1. O-O' denotes the centre line of welded plate. The remaining part of the plate was discarded to neglect the initial and end effect of heat input. In order to see the effect of number of passes on HAZ on top surface and in cross section, the samples of size $50 \mathrm{~mm} \times 10 \mathrm{~mm} \times 3 \mathrm{~mm}$ from " $\mathrm{B}$ " and " $\mathrm{C}$ " denoted by ' $\mathrm{X}$ ' and ' $\mathrm{Y}$ ' respectively were carefully cut using WEDM as shown in Fig. 1.

The sample preparation for " $\mathrm{X}$ " and " $\mathrm{Y}$ " is as follows. A copper strip was fixed to one side of sample using silver paste and a copper wire was soldered to the copper strip for electrical connections. The other side was kept open for etching and electrochemical tests. The assembly was then mounted in cold setting resin. The open surface of sample was polished on emery papers $(180,240,400,600$ and 800 grit), and then on velvet cloth smeared with $0.75 \mu$ alumina $\left(\mathrm{Al}_{2} \mathrm{O}_{3}\right)$ slurry. The samples were ultrasonically cleaned in distilled water at each stage of polishing. To identify the fusion zone and HAZ, surface area of $50 \mathrm{~mm} \times 10 \mathrm{~mm}$ in case of top surface and $50 \mathrm{~mm} \times 3 \mathrm{~mm}$ in case of crosssection respectively was used for electrolytic etching by ASTM standard A-262 Practice A. In Practice A, the samples were electrolytically etched in $10 \mathrm{wt} \%$ oxalic acid solution with current density of $1 \mathrm{~A} / \mathrm{cm}^{2}$ for 90 seconds. ${ }^{26)}$ Surface area of $10 \mathrm{~mm} \times 10 \mathrm{~mm}$ and $35 \mathrm{~mm} \times 3 \mathrm{~mm}$ of sample ' $\mathrm{X}$ ' and "Y" respectively was exposed for etching and remaining part of the samples was protected using teflon tape, which was also then etched in similar manner. The samples were then examined under optical microscope (Zeiss Axiolab) and scanning electron microscope (JEOL 6380A).

Double loop electrochemical potentiodynamic reactivation (DLEPR) test was performed in the sensitized region of true HAZ (refer Fig. 3) in the sample "Y", which was identified by Practice A. The test was carried out in a solution consisting of $0.5 \mathrm{M} \mathrm{H}_{2} \mathrm{SO}_{4}+0.01 \mathrm{M} \mathrm{NH}_{4} \mathrm{SCN}$ at room temperature $\left(27^{\circ} \mathrm{C}\right)$ using Potentiostat (Solartron-1285). A conventional three-electrode electrochemical cell with platinum electrode as counter electrode, saturated calomel electrode (SCE) as the reference electrode and sample as working electrode was employed. Before exposing working electrode, the test solution was de-aerated using dry (oxygen free) nitrogen gas for 1 hour. The experiments were initiated after nearly steady-state open circuit potential (OCP) had reached (about $45 \mathrm{~min}$ ). The test was performed at scan rate of $6 \mathrm{~V} / \mathrm{h}$ and the potential range was from $-500 \mathrm{mV}$ (SCE) to $+300 \mathrm{mV}$. This gives the forward scan. The scanning direction was then reversed, and the potential was then reduced back to $-500 \mathrm{mV}$ to obtain reverse scan. The peak activation current density $\left(\mathrm{I}_{\mathrm{a}}\right)$ and the peak reactivation current density $\left(\mathrm{I}_{\mathrm{r}}\right)$ were measured during forward and reverse scans, respectively. The \% DOS (degree of sensitization) was then computed as the ratio of $\left(\mathrm{I}_{\mathrm{r}} / \mathrm{I}_{\mathrm{a}}\right) \times 100 .{ }^{27-29)}$

The remaining sample ' $\mathrm{A}$ ' was polished up to 600 grit, ultrasonically cleaned with distilled water. Then these samples were subjected to ASTM standard A-262 Practice E test (Strauss test). ${ }^{26)}$ In Practice E, the samples were exposed in boiling solution of $16 \% \mathrm{H}_{2} \mathrm{SO}_{4}+100 \mathrm{gl}^{-1} \mathrm{CuSO}_{4}$ (in pres- 


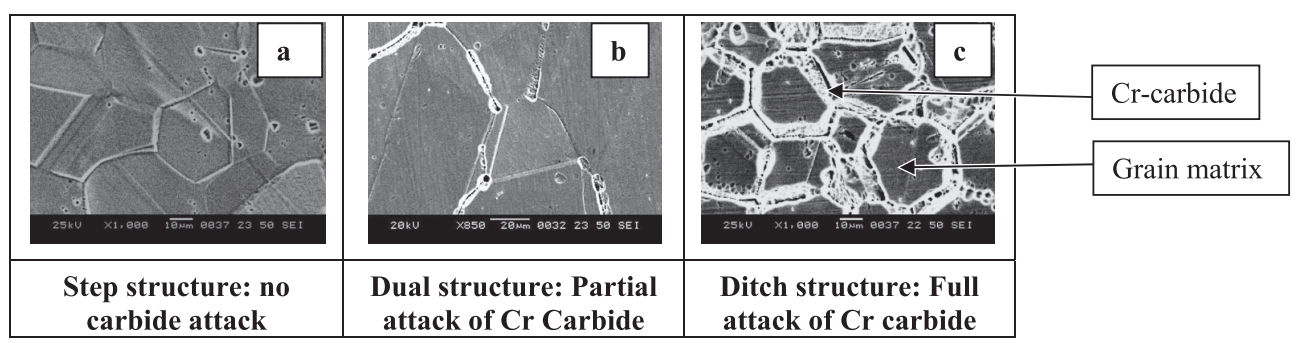

Fig. 2. SEM micrographs of welded Cr-Mn ASS as per ASTM standard A-262 Practice A: a) step structure b) dual structure c) ditch structure.

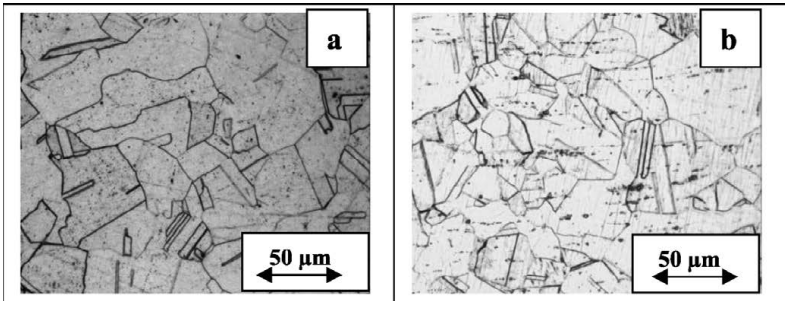

Fig. 3. Optical Micrographs as per ASTM standard A-262 Practice A test a) AISI $304 \mathrm{SS}$ b) Cr-Mn ASS.

ence of $\mathrm{Cu}$ turnings) for 24 hours. After that, the samples were removed, rinsed with distilled water, dried and stored in desiccators. Then they were subjected to tensile tests. The tensile specimens had gauge length of $50 \mathrm{~mm}$ and they were fractured in an INSTRON 4467 with a cross head speed of $10 \mathrm{~mm} / \mathrm{min}$. The fractured surfaces of the tensile specimens were studied using SEM JEOL $6380 \mathrm{~A}$. All specimens were examined at an acceleration voltage of $20 \mathrm{kV}$.

The chemical composition of the alloying elements across the grain boundaries was obtained using Electron Probe Micro analyzer (EPMA). The EPMA line scans of HAZ in cross-section of welded AISI 304 SS and Cr-Mn ASS after third pass was obtained in conjunction with SEM using JEOL 8600M Electron Probe Micro analyzer. The scan was performed for a set of 25 data points.

\section{Results and Discussion}

Typical SEM micrographs of step, dual and ditch structures as per ASTM standard A-262 Practice A test are shown in Figs. 2(a)-2(c). They are classified as follows ${ }^{26}$

1. Step structure: Steps only between grains, no ditches at grain boundaries.

2. Dual structure: Some ditches at grain boundaries in addition to steps, but no single grain completely surrounded by ditches.

3. Ditch structure: One or more grain completely surrounded by ditches.

Figures 3(a) and 3(b) shows the optical micrograph of solution annealed AISI 304 SS and Cr-Mn ASS after etching as per ASTM standard A-262 Practice A test. It is observed that both the steels before subjected to welding have single phase austenitic structure and no traces of carbides are found.

\subsection{Microstructural Study of Top Surface}

Figure 4 shows the schematic representation of various regions of welded plate. The microstructures obtained

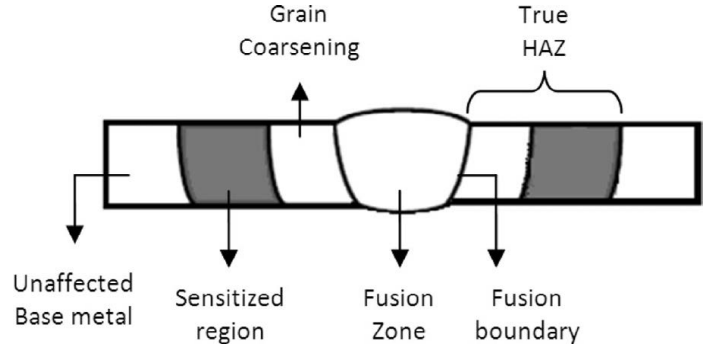

Fig. 4. Schematic of various regions of weldment.

showed a similar pattern as shown in figure. The true HAZ includes the region where microstructures have been altered due to both grain coarsening and carbide precipitation. Generally, the true HAZ is adjacent to the fusion boundary. The width of sensitized region in HAZ is a part of true HAZ, where only carbide precipitation has taken place. For ASS, the sensitized region is a serious cause of concern because numerous failures occur in this particular region as the steel is susceptible to IGC. . $^{12,13)}$

Considering the fusion boundary as a reference, the microstructures were observed at every $1 \mathrm{~mm}$ distance on the welded plate along longitudinal direction in order to identify the HAZ. Figures 5(a)-5(f) shows the optical micrographs of top surface of AISI 304 SS and Cr-Mn ASS for single, double and triple passes. The details obtained from the microstructures viz. true HAZ and width of sensitized region in HAZ are presented in Table 2. Figures 5(a)5 (b) shows the grain coarsening in both the steels when subjected to single pass, but no traces of carbides can be seen. From Table 2, it can be seen that the true HAZ for single pass welding of both the steels is $2 \mathrm{~mm}$, and no sensitized region in true HAZ was present. Hence, only grain coarsening was observed on the top surface when submitted to single pass welding. Thus, for the given heat input, both the steels are not prone to sensitization on the top surface during single pass welding.

However, a partial attack of carbide precipitation (dual structure) is observed when the steels are subjected to double pass welding (see Figs. 5(c)-5(d)). The severity of attack is less in AISI $304 \mathrm{SS}$ as the grain boundaries are observed to be very thin as compared to $\mathrm{Cr}-\mathrm{Mn}$ ASS. The true HAZ in AISI 304 SS included only sensitized region of $3 \mathrm{~mm}$ (see Table 2). For Cr-Mn ASS, true HAZ is spread over a distance of $5 \mathrm{~mm}$ from fusion boundary and grain coarsening was observed till $2 \mathrm{~mm}$ from fusion boundary, and the sensitized region was $3 \mathrm{~mm}$. Figures 5(e)-5(f) shows the micrographs after triple pass welding. A lightly attacked ditch structure was observed in case of AISI 304 SS, whereas a 


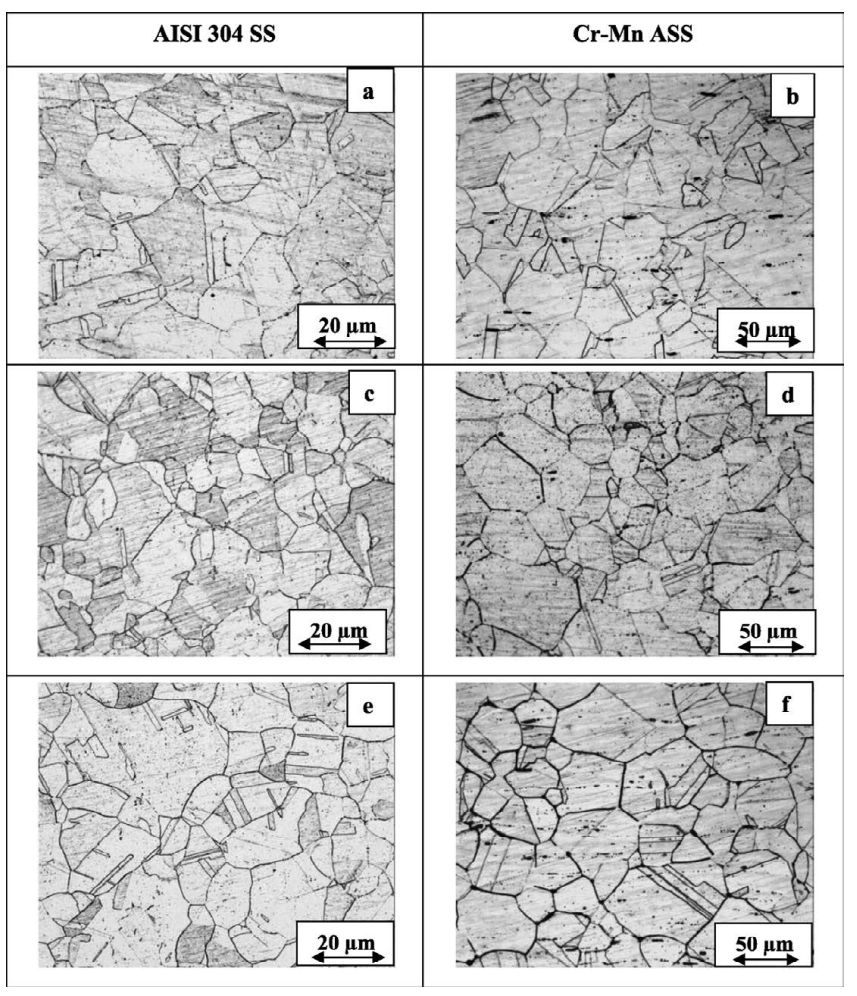

Fig. 5. Optical micrographs of top surface as per ASTM standard A-262 practice A test for single pass (a-b); double pass (cd); triple pass (e-f)

Table 2. Data obtained from microstructures of top surface.

\begin{tabular}{c|ccc}
\hline Steel & $\begin{array}{c}\text { Number of } \\
\text { Passes }\end{array}$ & $\begin{array}{c}\text { True HAZ } \\
(\mathrm{mm})\end{array}$ & $\begin{array}{c}\text { Width of Sensitized region } \\
\text { in HAZ }(\mathrm{mm})\end{array}$ \\
\hline \multirow{3}{*}{ AISI 304 SS } & Single & 2 & 0 \\
& Double & 3 & 3 (dual) \\
& Triple & 5 & 5 (lightly ditch) \\
\hline \multirow{3}{*}{ Cr-Mn ASS } & Single & 2 & 0 \\
& Double & 5 & 3(dual) \\
& Triple & 9 & 6 (heavily ditch) \\
\hline
\end{tabular}

fully ditch structure for $\mathrm{Cr}-\mathrm{Mn}$ ASS was observed. Also, the sensitization region for $\mathrm{Cr}-\mathrm{Mn}$ ASS was measured to be 6 $\mathrm{mm}$, whereas for AISI 304 SS it was $5 \mathrm{~mm}$.

Hence, it can be seen that the low-level intensity of attack is increasing from single to triple pass welding for given heat input for both the steels. But, still no inferences can be drawn based only on the micrographs of top surface. So, a detailed study of cross-section of the welded plate has been carried out.

\subsection{Microstructural Study of Cross-section}

Figures 6(a)-6(f) shows the optical micrographs of crosssection of AISI $304 \mathrm{SS}$ and $\mathrm{Cr}-\mathrm{Mn}$ ASS for single, double and triple passes. From Figs. 6(a), 6(c) and 6(e), it can be confirmed that for AISI 304 SS, the extent of carbide precipitation increases with increase in number of passes. That is the AISI 304 SS when subjected to triple pass welding, gets highly sensitized. A similar trend can be seen in case of Cr-Mn ASS. From Figs. 6(a)-6(b) and Table 3, it can be noticed that a dual structure is observed over a region of 4 $\mathrm{mm}$ and $2 \mathrm{~mm}$ for AISI $304 \mathrm{SS}$ and Cr-Mn ASS, respec-

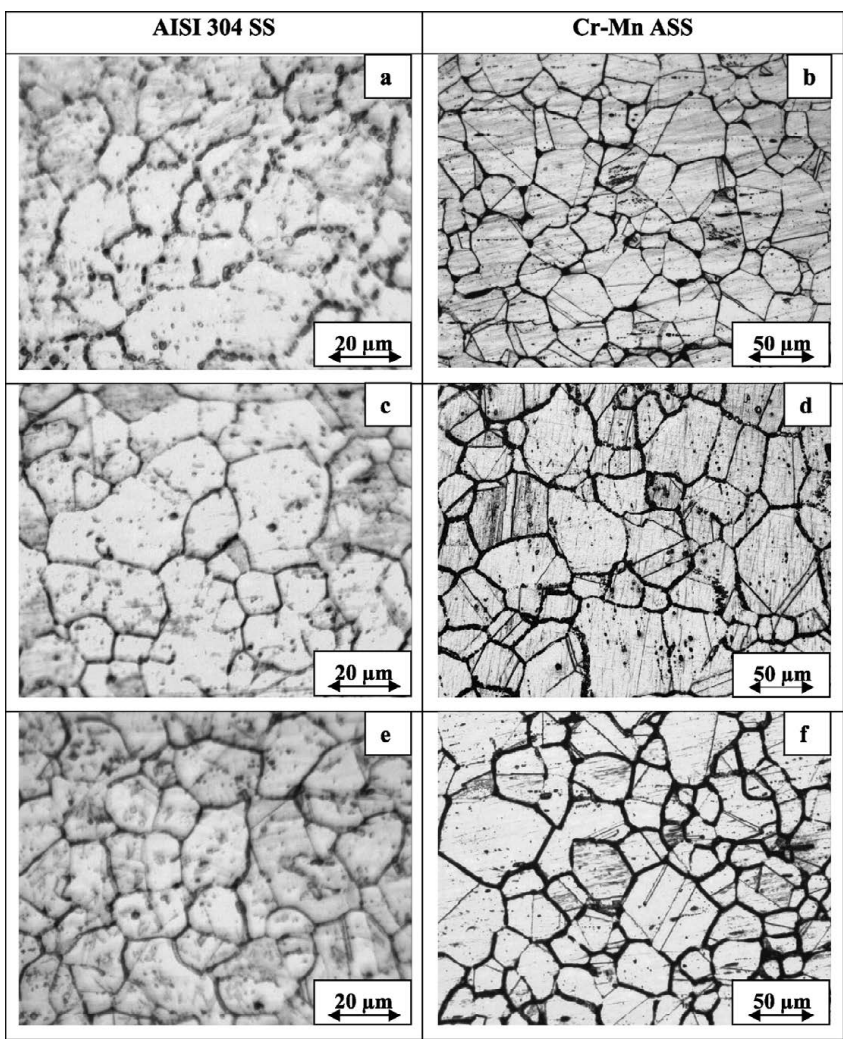

Fig. 6. Optical micrographs of cross-section as per ASTM standard A-262 practice A test for single pass (a-b); double pass (cd); triple pass (e-f).

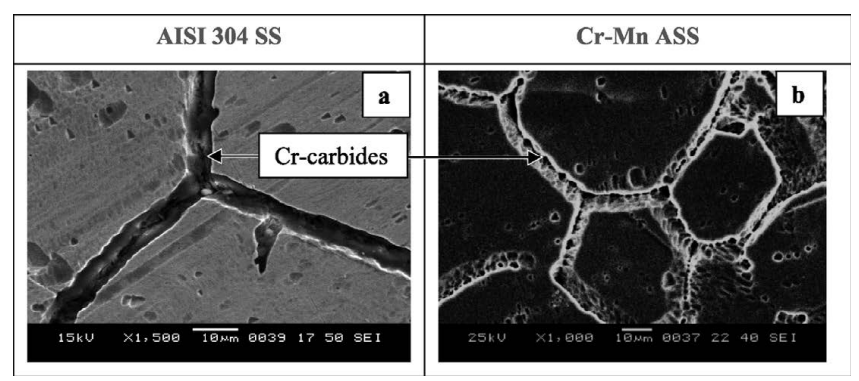

Fig. 7. SEM micrographs of cross-section as per ASTM standard A-262 practice A test after third pass of welding.

Table 3. Data obtained from microstructures of cross-section.

\begin{tabular}{c|ccc}
\hline \multirow{2}{*}{ Steel } & $\begin{array}{c}\text { Number of } \\
\text { Passes }\end{array}$ & $\begin{array}{c}\text { True HAZ } \\
(\mathrm{mm})\end{array}$ & $\begin{array}{c}\text { Width of Sensitized region } \\
\text { in HAZ }(\mathrm{mm})\end{array}$ \\
\hline \multirow{3}{*}{ AISI 304 SS } & Single & 5 & 4 \\
& Double & 7 & 7 \\
& Triple & 8 & 8 \\
\hline \multirow{3}{*}{ Cr-Mn ASS } & Single & 5 & 2 \\
& Double & 8 & 4 \\
& Triple & 11 & 7 \\
\hline
\end{tabular}

tively. For double and triple pass welding in AISI 304 SS (from Table 3), no grain coarsening was observed and sensitized region was spread over $7 \mathrm{~mm}$ and $8 \mathrm{~mm}$ respectively. From Figs. 6(d) and 6(f) and Table 3, the values of true HAZ and width of sensitized region indicate that there was grain coarsening near the fusion boundary, whereas a rigorous attack of carbide precipitation can be seen for double and 
triple pass welding in $\mathrm{Cr}-\mathrm{Mn}$ ASS.

Figures 7(a) and 7(b) shows SEM micrographs of crosssection of AISI 304 SS and Cr-Mn ASS after third pass of welding. The micrographs confirm the existence of $\mathrm{Cr}$ carbides at the grain boundaries. The severity of $\mathrm{Cr}$-carbide precipitation at grain boundaries is more in case of $\mathrm{Cr}-\mathrm{Mn}$ ASS than AISI 304 SS, after third pass of welding.

Therefore, it is concluded from optical and SEM micrographs, that the $\mathrm{Cr}-\mathrm{Mn}$ ASS is highly susceptible to IGC for all the passes of welding, but the extent of $\mathrm{Cr}$ - depletion is very high in $\mathrm{Cr}-\mathrm{Mn}$ ASS after third pass.

\subsection{Results of DLEPR Test}

Figures 8(a) and 8(b) shows the DLEPR curves for solution annealed AISI $304 \mathrm{SS}$ and $\mathrm{Cr}-\mathrm{Mn}$ ASS respectively. The activation peak current density $\left(\mathrm{I}_{\mathrm{a}}\right)$, reactivation peak current density $\left(I_{r}\right)$ and \% DOS are presented in Table 4. The $\mathrm{I}_{\mathrm{r}}$ value for $\mathrm{Cr}-\mathrm{Mn}$ ASS is nearly one order magnitude

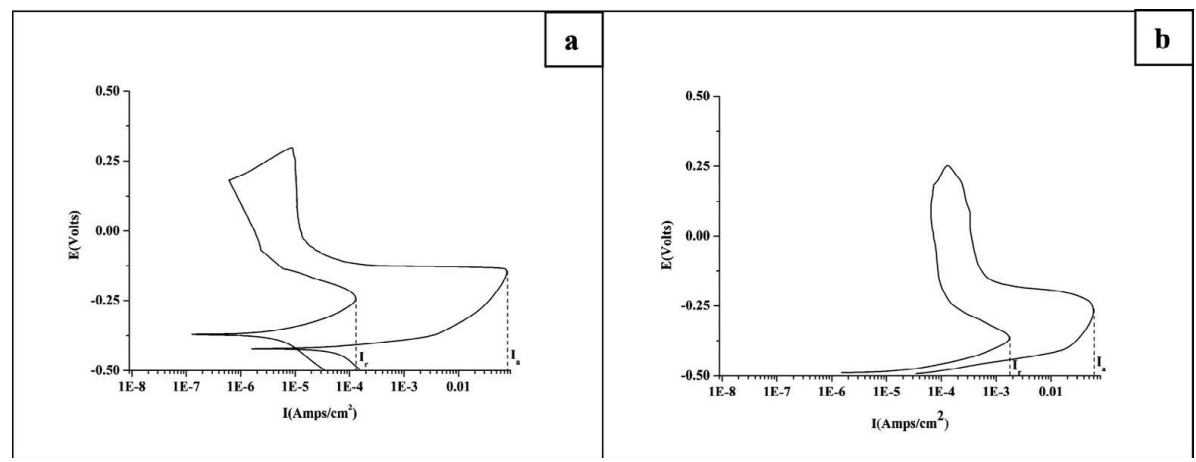

Fig. 8. DLEPR curves for solution annealed: a) AISI $304 \mathrm{SS}$ b) $\mathrm{Cr}-\mathrm{Mn}$ ASS

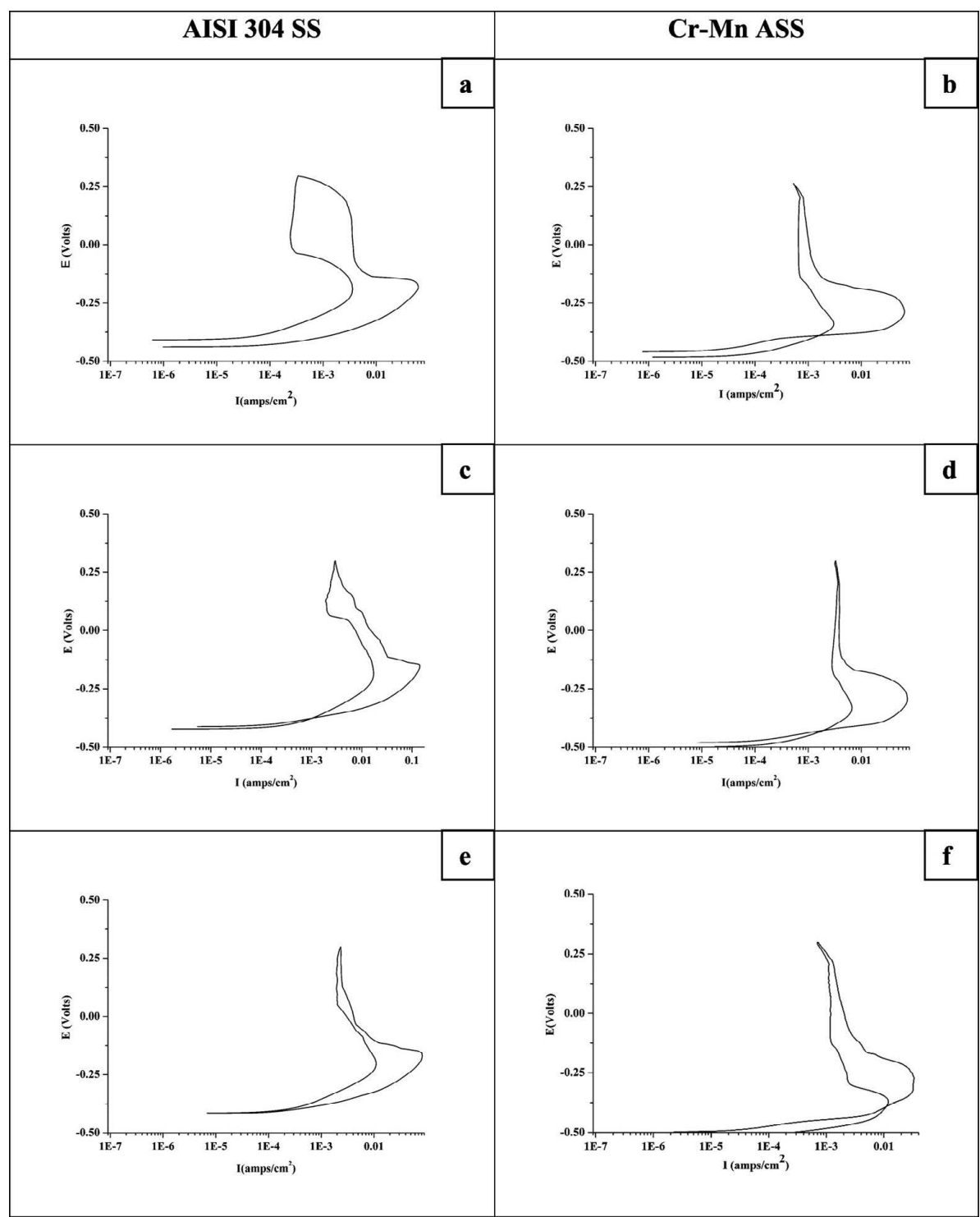

Fig. 9. DLEPR curves of cross-section for single pass (a-b); double pass (c-d); triple pass (e-f). 
more than that of AISI 304 SS. The development of the reactivation peak current density can be attributed to metal dissolution during reverse scan. This means that the passive film formed on the surface of Cr-Mn ASS has lower corrosion resistance as compared to AISI 304 SS. A ratio of maximum current generated in the DLEPR test $\left(I_{\mathrm{r}} / \mathrm{I}_{\mathrm{a}}\right)$ is used as a measure for the "degree of sensitization (DOS)". ${ }^{3)}$ The \% DOS of solution annealed Cr-Mn ASS shows value of 2.92, whereas for AISI $304 \mathrm{SS}$, it is $0.17 \%$. But, from Figs. 3(a) and 3(b), it can be seen that both the steels when solution annealed have single phase austenitic structure. The exceptionally high value of $\%$ DOS in $\mathrm{Cr}-\mathrm{Mn}$ ASS was due to the less amount of $\% \mathrm{Cr}$ present in this steel.

The optical micrographs of welded samples in crosssection showed significant results in terms of sensitized region in true HAZ. But, the micrographs give only the nature of sensitization viz. step, dual or ditch, or in other words, it only provides the qualitative information. Therefore, quantification of sensitized region was carried out in terms of $\%$ DOS. The DLEPR curves of cross-section for single, double and triple pass welding of both the steels are shown in Figs. 9(a)-9(f). The results obtained from these curves are presented in Table 4.

The $\mathrm{I}_{\mathrm{r}}$ values increases with increase in number of welding passes in case of both the steels. It indicates that the passive film is easily dissolved in triple pass than in single and double passes. It is also evident in the form of $\%$ DOS, that

Table 4. Data obtained from DLEPR curves.

\begin{tabular}{cllr}
\hline Number of passes & $\mathrm{I}_{\mathrm{r}}\left(\mathrm{A} / \mathrm{cm}^{2}\right)$ & $\mathrm{I}_{\mathrm{a}}\left(\mathrm{A} / \mathrm{cm}^{2}\right)$ & \%DOS \\
\hline \multicolumn{4}{c}{ AISI 304 SS } \\
\hline Solution Annealed & 0.000130 & 0.077034 & 0.17 \\
Single pass & 0.003183 & 0.075629 & 4.20 \\
Double pass & 0.011061 & 0.15265 & 7.24 \\
Triple pass & 0.013001 & 0.082212 & 13.38 \\
\hline \multicolumn{4}{c}{$\mathrm{Cr}-\mathrm{Mn}$ ASS } \\
\hline Solution Annealed & 0.001731 & 0.595287 & 2.92 \\
Single pass & 0.003821 & 0.060848 & 6.27 \\
Double pass & 0.006646 & 0.061315 & 10.83 \\
Triple pass & 0.011912 & 0.033535 & 35.53 \\
\hline
\end{tabular}

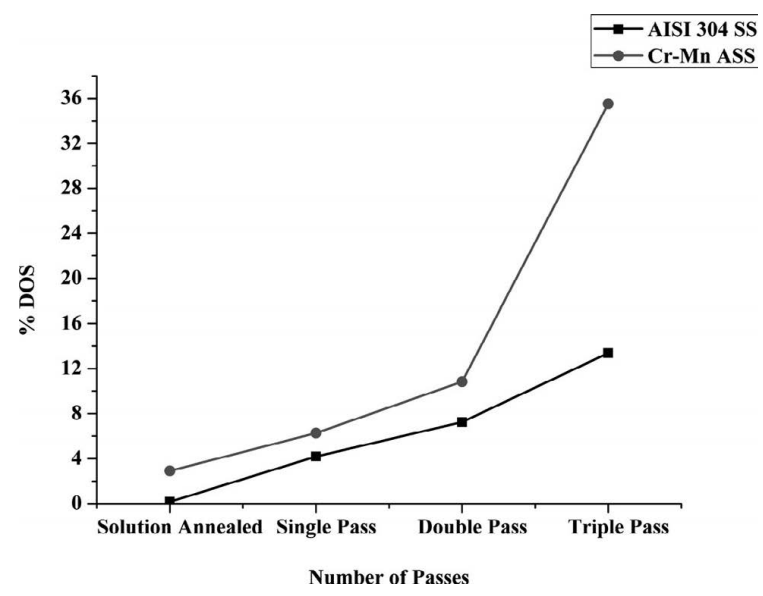

Fig. 10. Relationship between number of passes and \% DOS of cross-section. is, the \% DOS for triple pass welding is higher than the other passes (see Table 4). These results are in good agreement with the optical and SEM micrographs of cross-section (see Figs. 6(a) $-6(\mathrm{f})$ and $7(\mathrm{a})-7(\mathrm{~b})$.

The effect of number of passes on $\%$ DOS of cross-section for AISI $304 \mathrm{SS}$ and $\mathrm{Cr}-\mathrm{Mn}$ ASS is plotted and presented in Fig. 10. From Table 4, for single pass welding, the \% DOS values are 4.20 and 6.27 for AISI 304 SS and $\mathrm{Cr}-\mathrm{Mn}$ ASS respectively. It means that the sensitized region of $\mathrm{Cr}-$ Mn ASS which was exposed in DLEPR test is more susceptible to IGC as compared to AISI 304 SS. Similar inferences can be drawn for double and triple pass welding. Amongst sensitized regions of all the passes, the highest \% DOS (35.53) was obtained for triple pass welding of Cr-Mn ASS. This can also be correlated with its micrograph (see Figs. $6(\mathrm{f})$ and $7(\mathrm{~b})$.

Hence, from qualitative and quantitative tests, it is concluded that Cr-Mn ASS is more susceptible to IGC as compared to AISI 304 SS, when subjected to welding. $\mathrm{Cr}-\mathrm{Mn}$ ASS was badly affected due to IGC in HAZ because of its high carbon and low chromium content. This ill-effect of sensitization will be reflected in the mechanical properties. The next section deals with effect of number of passes on the tensile strength of both the steels.

\subsection{Tensile Test and Fractography}

The effect of number of passes on the tensile properties of AISI 304 SS and Cr-Mn ASS was studied by performing tensile tests on the welded samples. The variation in the tensile strength of both the steels with number of passes is depicted in Fig. 11.

It can be seen that there is a significant reduction in tensile strength with increasing number of passes. However, the decrease in tensile strength is relatively more in $\mathrm{Cr}-\mathrm{Mn}$ ASS as compared to AISI 304 SS. The tensile strengths of solution annealed specimen of AISI 304 SS and Cr-Mn ASS are $562 \mathrm{MPa}$ and $626 \mathrm{MPa}$ respectively. The tensile strengths of AISI $304 \mathrm{SS}$ were obtained as 530, 505 and $460 \mathrm{MPa}$, whereas for Cr-Mn ASS, they were 561, 503 and $406 \mathrm{MPa}$, when subjected to single, double and triple pass of welding respectively. The reduction in tensile strength with the number of passes can be attributed to increase in chromium carbide precipitation in the sensitized zone, which can be

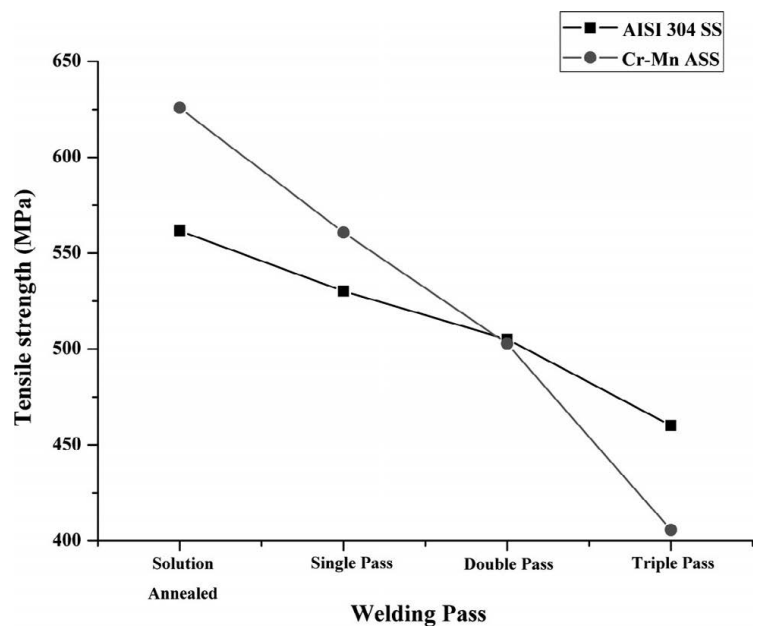

Fig. 11. Relationship between tensile strength and welding pass. 


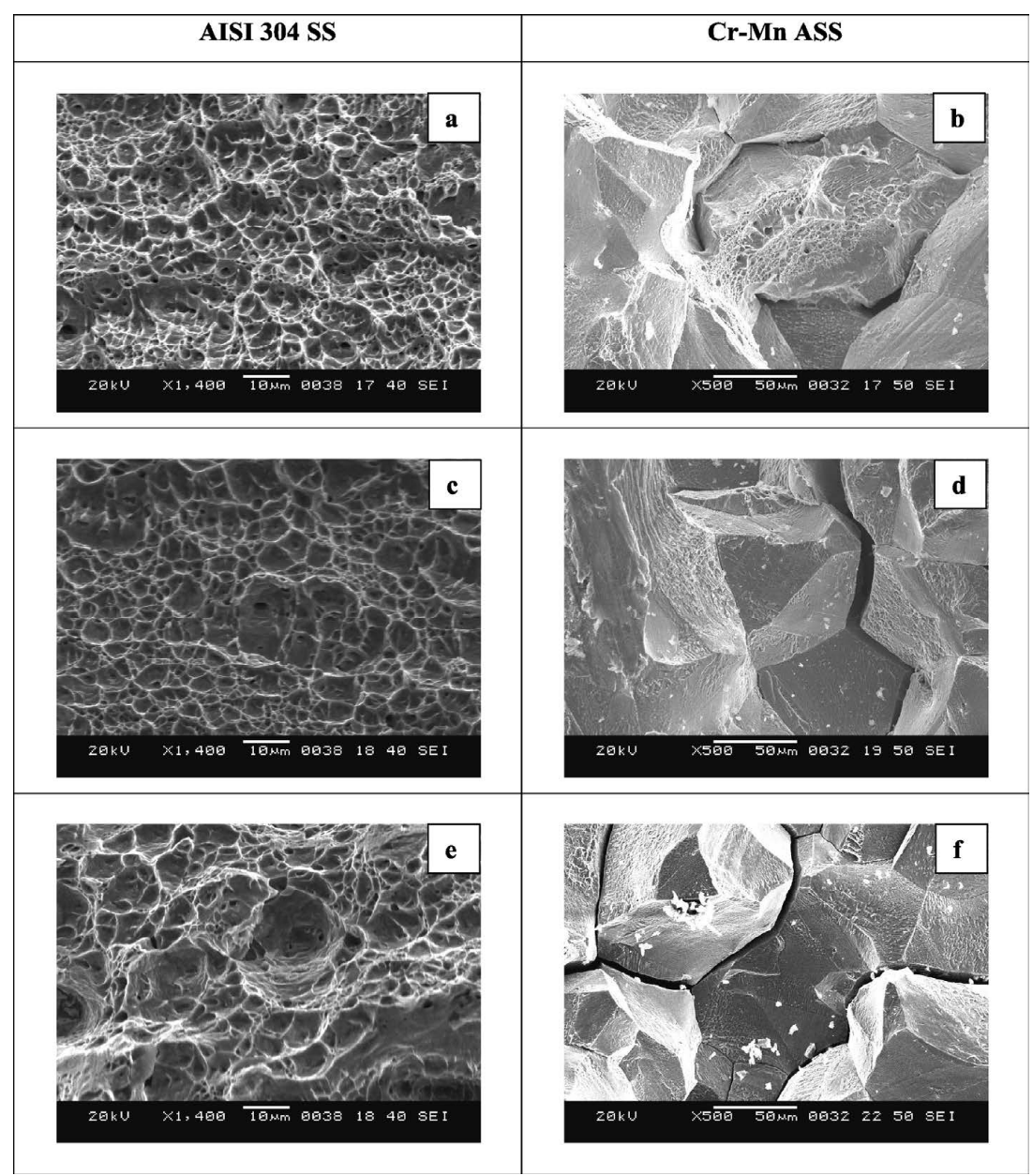

Fig. 12. SEM fractograph of the tensile specimen for single pass (a-b); double pass (c-d); triple pass (e-f).

observed from the micrographs of cross-section. This reduction is also due to the increase in severity of IGC during $\mathrm{E}$ test. The minimum tensile strength value was obtained for triple pass welding of $\mathrm{Cr}-\mathrm{Mn}$ ASS, whose \% DOS was also observed to be the highest.

The fractured surfaces of the tensile specimens of welded AISI 304 SS and Cr-Mn ASS were observed to characterize the failure modes and the SEM fractographs are shown in Figs. 12(a)-12(f). From the fractographs, it was observed that AISI 304 SS failed due to ductile fracture. The fractured surfaces of AISI 304 SS showed wide range of dimple sizes of equiaxed type (see Figs. 12(a), 12(c) and 12(e)). The dimple structure formation takes place due to micro void initiation around the carbide particles which are precipitated along the grain boundary during sensitization. In case of single pass welding, dual nature of carbide precipitation was observed in the sensitized zone (see Fig. 6(a)) and hence fine dimples were found, whereas the dimple size increase subsequently for double pass and triple pass of welding.

Figures 12(b), 12(d) and 12(f) shows the fractured surfaces of welded $\mathrm{Cr}-\mathrm{Mn}$ ASS. A mixed type of fracture was observed in case of single and double passes welding, whereas the intergranular brittle fracture was observed in triple pass welding. In single pass welding (see Fig. 12(b)), intergranular brittle fracture is dominant along with slight ductile fracture. Intergranular brittle fracture was observed due to variation in segregation of carbide particles at grain boundaries, whereas very fine dimples indicate the ductile

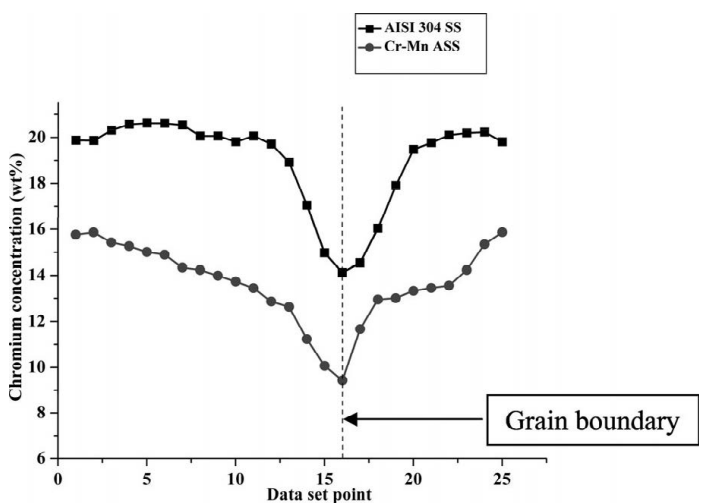

Fig. 13. EPMA line scan to identify $\mathrm{Cr}$ concentration of $\mathrm{HAZ}$ in cross section after third pass of welding.

fracture. In double pass welding (see Fig. 12(d)), intergranular brittle fracture and transgranular cleavage was observed. The transgranular cleavage is characterized by river pattern. Secondary fracture was also observed at few places where the grain boundaries were highly attacked by carbide precipitation. In case of triple pass welding, the attack of carbide precipitation at grain boundaries was very high, and continuous, and hence it failed due to intergranular brittle fracture. The secondary fracture can be predominantly seen in triple pass welding, and it was responsible for the decreased tensile strength.

The chemical composition of the alloying elements across 
the grain boundaries was obtained using Electron Probe Micro analyzer (EPMA). Figure 13 shows the Chromium depletion of HAZ in cross-section after third pass of welding of AISI 304 SS and $\mathrm{Cr}-\mathrm{Mn}$ ASS. The Cr-depleted region for $\mathrm{Cr}-\mathrm{Mn}$ ASS is much wider than that of AISI 304 $\mathrm{SS}$. The minimum $\mathrm{Cr}$-concentration at the grain boundary in the depleted region for AISI $304 \mathrm{SS}$ and $\mathrm{Cr}-\mathrm{Mn}$ ASS is $\sim 15.3$ $\mathrm{wt} \%$ and $\sim 9 \mathrm{wt} \%$ respectively. The minimum $\mathrm{Cr}$-concentration drops significantly, which is attributed to detrimental attack of IGC in HAZ in case of Cr-Mn ASS. The EPMA line scan results are also in good agreement with \% DOS (35.53) in $\mathrm{HAZ}$ for triple pass welding of $\mathrm{Cr}-\mathrm{Mn}$ ASS. From these results it is concluded that the passive protective oxide film of $\mathrm{Cr}_{2} \mathrm{O}_{3}$ became very weak for $\mathrm{Cr}-\mathrm{Mn}$ ASS after third pass of welding. This is due to the fact that carbon content is very high in $\mathrm{Cr}-\mathrm{Mn}$ ASS (C $-0.11 \mathrm{wt} \%$ ) as compared to AISI $304 \mathrm{SS}$ (C - $0.054 \mathrm{wt} \%$ ). This high $\mathrm{C}$ content in $\mathrm{Cr}-\mathrm{Mn}$ ASS increases the kinetics of sensitization in HAZ and therefore $\mathrm{Cr}$-carbides precipitated at a very faster rate at the grain boundaries after third pass of welding.

\section{Conclusions}

(1) In case of top surface, for all the passes of welding AISI 304 SS did not show any significant carbide precipitation and grain coarsening, whereas fully ditch structure and significant grain coarsening for $\mathrm{Cr}-\mathrm{Mn}$ ASS was observed only after triple pass of welding.

(2) In case of cross section, the extent of carbide precipitation increased with increase in number of passes for both the steels. But, the severity of carbide attack was more in $\mathrm{Cr}-\mathrm{Mn} \mathrm{ASS}$, although the width of sensitized region was less as compared to AISI $304 \mathrm{SS}$.

(3) From DLEPR results, it is concluded that the sensitized region of $\mathrm{Cr}-\mathrm{Mn}$ ASS is more susceptible to IGC than AISI 304 SS. The highest \% DOS (35.53) was obtained for triple pass welding of $\mathrm{Cr}-\mathrm{Mn}$ ASS.

(4) It is concluded from qualitative and quantitative tests that the $\mathrm{Cr}-\mathrm{Mn}$ ASS is more susceptible to IGC as compared to AISI 304 SS for all the passes of welding.

(5) There was a significant reduction in tensile strength with increasing number of passes. However, the decrease in tensile strength is relatively more in $\mathrm{Cr}-\mathrm{Mn}$ ASS as compared to AISI 304 SS.

(6) AISI $304 \mathrm{SS}$ failed due to ductile fracture for all the passes of welding. In $\mathrm{Cr}-\mathrm{Mn} \mathrm{ASS}$, mixed types of fracture was observed in single and double pass welding, whereas the intergranular fracture was observed in triple pass welding.

(7) EPMA line scan results confirmed that the minimum $\mathrm{Cr}$-concentration value at grain boundary attributed to detrimental attack of IGC in HAZ in case of $\mathrm{Cr}-\mathrm{Mn}$ ASS after third pass of welding.

\section{Acknowledgements}

The authors would like to thank Director, VNIT Nagpur for providing the necessary facilities for carrying out this investigation and for his constant encouragement to publish this work. The authors are grateful to Shri Ved Prakash Sabarwal, Emfab Engineers, MIDC, Nagpur for providing welding set-up in his workshop. The authors are also thankful to Mr. Jagdish Singh, (Scientific Officer Gd.-II) at Indian Institute of Technology Roorkee for conducting EPMA line scans.

\section{REFERENCES}

1) A. J. Sedriks: Corrosion of Stainless Steels, 2nd ed., J. Wiley \& Sons, New York, (1996), 13.

2) G. George and H. Shaikh: Corrosion of Austenitic Stainless Steels: Mechanism, Mitigation and Monitoring, ed. by H. S. Khatak and B. Raj, Woodhead Publishing House, Cambridge, England, (2002), 1.

3) G. H. Aydogфdu and M. K. Aydinol : Corros. Sci., 48 (2006), 3565.

4) J. C. Lippold and D. J. Kotecki: Welding Metallurgy and Weldability of Stainless Steels, John Wiley \& Sons Inc. UK, (2005), 141.

5) R. V. Taiwade, S. J. Patre and A. P. Patil: Trans. Indian Inst. Met., 64 (2011), No. 6, 513.

6) R. L. Plaut, C. Herrera, D. M. Escriba, P. R. Rios and A. F. Padilha: Mater. Res., 10 (2007), No. 4, 453.

7) 200-Series Stainless Steel-CrMn Grades, ASSDA Technical Bulletin, 1st ed., ASSDA, Australia, (2006).

8) V. Shankar Rao and L. K. Singhal: ISIJ Int., 49 (2009), No. 12, 1902.

9) T. Oshima, Y. Habara and K. Kuroda: ISIJ Int., 47 (2007), No. 3, 359.

10) "New 200-series" steels, An Opportunity or A Threat to the Image of Stainless Steel? ISSF, Brussels, Belgium, (2005).

11) N. Parvathavarthini: Corrosion of Austenitic Stainless Steels: Mechanism, Mitigation and Monitoring, ed. by H.S. Khatak and B. Raj, Woodhead Publishing House, Cambridge, England, (2002), 117.

12) M. G. Fontana: Corrosion Engineering, 3rd ed., Tata McGraw Hill Education Pvt. Ltd., New York, (2005), 78.

13) R. K. Dayal, N. Parvathavarthini and B. Raj: Int. Mater. Rev., 50 (2005), 129.

14) H. Sheikh: In Corrosion of Austenitic Stainless Steels: Mechanism, Mitigation and Monitoring, ed. by H. S. Khatak and B. Raj, Wood head Publishing House, Cambridge, England, (2002), 166.

15) S. Kou: Welding Metallurgy, 2nd ed. John Wiley \& Sons Inc., New York, (2003).

16) J. R. Davis: Corrosion of Weldments, ASM International, Materials Park, OH, (2006), 43.

17) R. S. Parmar: Welding Engineering and Technology, 1st ed., Khanna Publication, New Delhi, India, (2004), 543.

18) N. Parvathavarthini, R. K. Dayal, H. S. Khatak, V. Shankar and V. Shanmugam: J. Nucl. Mater., 355 (2006), 68.

19) Y. C. Lin and K. H. Lee: J. Mater Process. Technol., 63 (1997), 797.

20) C. C. Silva, J. P. Farias and H. B. de Sant Ana: Mater. Design, 30 (2009), 1581.

21) A. S. Afolabi: $A U J . T ., 11$ (2008), 171.

22) S. Kumar and A. S. Shahi: Mater. Design, 32 (2011), 3617.

23) A. Y. Kina, V. M. Souza, S. S. M. Tavares, J. M. Pardal and J. A. Souza: Mater. Charact., 59 (2008), 651.

24) N. Srisuwan: The 2nd RMUTP Int. Conf., Green Technology and Productivity Bangkok, Thailand, (2010), 102.

25) S. Murugan, P.V. Kumar, B. Raj and M. S. C. Bose: Int. J. Pres. Ves. Pip., 75 (1998), 891.

26) Recommended Practices for Detecting Susceptibility to Intergranular Corrosion in Stainless Steels, A-262-02, ASTM Annual Book, ASTM Publications, Philadelphia, PA, 3.02 (2002).

27) Standard Test Method for Electrochemical Reactivation (EPR) for Detecting Sensitization of AISI Type 304 and 304L Stainless Steels, G-108-94, ASTM Publication, Philadelphia, (2010).

28) A. P. Majidi and M. A. Streicher: Corrosion, 40 (1984), 584.

29) T. Luz, J. P. Farias and P. Neto: Welding Int., 20 (2006), 959. 